Number 2005-33, November 30, 2005

\title{
Uncertainty and Monetary Policy
}

In any meeting of monetary policymakers, uncertainty is likely to play an important role in their deliberations. According to Alan Greenspan (2003), "Uncertainty is not just an important feature of the monetary policy landscape; it is the defining characteristic of that landscape." In fact, the recognition that all monetary policymakers must bow to the presence of uncertainty appears to underlie Greenspan's (2003) view that central banks are driven to a "risk-management" approach to policy, whereby policymakers "need to reach a judgment about the probabilities, costs, and the benefits of the various possible outcomes under alternative choices for policy."

Uncertainty comes in many forms. One obvious form is simply ignorance about the shocks that will disturb the economy in the future-oil price shocks are a good example. But other, perhaps more insidious, forms of uncertainty can have resounding implications for how policy should be conducted, three of which are data uncertainty, parameter uncertainty, and model uncertainty.

Since uncertainty is such an important issue for policymakers it should come as no surprise that economists have made a study of its various guises and developed formal techniques to help understand and mitigate its effects. In this Letter I discuss, in broad-brush terms, some of these techniques and their implications for the conduct of monetary policy.

\section{Data uncertainty}

One form of uncertainty that is ever present is data uncertainty. Consider the economy's real GDP. For each and every quarter of the year, three estimates of real GDP are released: an advance estimate, a preliminary estimate, and a final estimate. As successive estimates are released, a greater fraction of the estimate is actually measured and less is imputed. But some imputation is involved even for the final GDP release. In fact the final GDP estimate is not final. Every year a benchmark revision occurs in which previous estimates of real GDP are revised, going back several years. Try as we might, due to measurement difficulties of one sort or another, we can never know what the economy's real GDP actually is, or was. This is data uncertainty.

Orphanides (2001) makes an in-depth study of data revisions, including those to real GDP, emphasizing the point that any study of past policy decisions should be based on data that were available to policymakers at that time, not on data that have been subsequently revised. This is not a mere quibble. Orphanides shows that policy rules look very different when they are estimated on real-time data - that is on the data available at the time policy decisions were made-rather than on revised data. In particular, not using real-time data can give a very misleading impression of monetary policy's responsiveness to inflation.

A separate issue is how real-time monetary policy should be conducted when the central bank acknowledges data uncertainty, since a rule that performs well when there is no data uncertainty may prove disastrous when there is. Aoki (2003) examines this issue and obtains results that are reasonably intuitive: as the amount of measurement error, or data uncertainty, in a variable increases, the information content in that variable should be discounted. So the more poorly real GDP is measured, the less a policymaker should respond to movements in real GDP when conducting policy. In effect, data uncertainty provides reason to proceed cautiously, attenuating the response coefficients in an optimal policy rule.

\section{Parameter uncertainty}

Distinct from data uncertainty is parameter uncertainty. Economists use models to understand how the economy might respond when stimulated in certain ways, and to create forecasts. These economic models contain parameters that govern the interactions that occur within the model, such as how sensitive consumption or investment is to a 1 percentage point change in the real interest rate. While economists can use statistical techniques to try to estimate these parameters, ultimately their values remain very much uncertain quantities. 
How does parameter uncertainty affect how policymakers should conduct policy? An answer to this question was provided first in a paper by Brainard (1967). He argued that, in response to uncertainty about the parameter on a variable, policymakers should attenuate their policy response to movements in that variable. While the motivation is different, this answer is the same as that suggested by the literature on data uncertainty. Unfortunately, Brainard's finding, however intuitive, has been shown not to be general: some forms of parameter uncertainty suggest that policymakers should discount incoming data, but others suggest that policymakers should respond more aggressively to incoming data. For example, if there is uncertainty about the persistence of inflation, then it may pay for policymakers to respond aggressively to increases in inflation in order to guard against the possibility that shocks may have an enduring effect on inflation outcomes (Söderström 2002).

Some recent studies have found that parameter uncertainty is not such a big deal for policymakers. Rudebusch (2001) considers how parameter uncertainty affects the coefficients in an optimal policy rule using a macroeconometric model of the United States and finds that for his model the effects of parameter uncertainty are essentially negligible, certainty less important than those of data uncertainty. But while it is possible that uncertainty about model parameters may be reasonably benign from policymakers' perspective, this is not to say that uncertainty about the goals and conduct of monetary policy is benign from households' and firms' perspective. With respect to the latter, studies by Orphanides and Williams (2005) and Gurkaynak, Sack, and Swanson (2005) show that better policy outcomes can be obtained when households and firms are more certain of the economy's long-run average rate of inflation, highlighting one reason why some countries may have adopted policy regimes with explicit inflation targets.

\section{Model uncertainty and model averaging}

While there is uncertainty about the data that enter into economic models and about the parameters that govern economic models, the fact that economists often approach macroeconomic data armed with different models of the economy suggests that uncertainty, or ambiguity, about the model could also be potentially important. From a policymaking perspective, it is quite possible, indeed reasonable, to think that policymakers may have several models at their disposal, perhaps re- flecting competing economic theories, each of which could justifiably be viewed as a reasonable approximation of the interrelationships at work in the actual economy.

A policy can be made "robust" to model uncertainty by designing it to perform well on average across all of the available fully specified models rather than to reign supreme in any particular model (McCallum 1988). This model-averaging approach is taken in Levin, Wieland, and Williams (2003), who use five disparate macroeconometric models of the U. S. economy to study how best to conduct monetary policy when facing model uncertainty. Focusing on simple rules in which the Federal Reserve is assumed to set the federal funds rate in response to inflation, the output gap (that is, the difference between actual output and an estimate of potential output), and the lagged federal funds rate, they identify a particular policy rule that is able to perform well across all five models. The policy rule that they identify is one that contains a short-term forecast of future inflation, incorporates a large response to the output gap, and that involves considerable "gradualism," or interest rate smoothing.

Although the model averaging approach allows us to get a handle on how to think about model uncertainty at the level of the policymaker, it is less clear what the approach has to say about the views of the households and firms that make up the economy.

\section{Model uncertainty and robust control}

The model-averaging approach to model uncertainty is not possible when policymakers cannot articulate and specify the various models that they wish to be robust against and therefore cannot assign probabilities to each of the models. This situation is known as Knightian uncertainty (Knight 1921). In such environments, the robust control approach comes into play. Robust control suggests that policymakers should formulate policy to guard against the worst form of model misspecification that is possible. Thus, rather than focusing on the "most likely" outcome or on the average outcome, robust control argues that policymakers should focus on and defend against the worst-case outcome. While the robust control approach may suggest some paranoia on the part of the policymaker, the intuition for robust control can be found in such common expressions as "expect the unexpected" and "hope for the best, but prepare for 
the worst." A valuable feature of the robust control approach is that it allows us to think about and combine model misspecification from the perspective of the policymaker with model misspecification from the perspective of households and firms. After all, there is no reason to think that policymakers are the only people who have to worry about model misspecification.

In an interesting application of robust control methods, Sargent (1999) studies a simple macro-policy model and shows that robustness, in the "robust control" sense, does not necessarily lead to policy attenuation. Instead, the robust policy rule may respond more aggressively to shocks. The intuition for this result is that, by pursuing a more aggressive policy, the central bank can prevent the economy from encountering situations where model misspecification might be especially damaging.

\section{Conclusion}

Uncertainty comes in various forms and is something that policymakers must continually contend with. Economists have developed a range of formal methods for thinking about and analyzing uncertainty, all of which offer important insights into how policymakers might manage the problem. While attenuation, the notion that incoming data should be discounted, is an intuitive reaction to uncertainty, it is not always appropriate. Unfortunately, when dealing with uncertainty, there do not seem to be any hard and fast guidelines for policymakers.

\section{Richard Dennis Economist}

\section{References}

Aoki, Kosuke. 2003. "On the Optimal Monetary Policy Response to Noisy Indicators." Journal of Monetary Economics 50(3), pp. 501-523.
Brainard, William. 1967. "Uncertainty and the Effectiveness of Monetary Policy." American Economic Review 57(2), pp. 411-425.

Greenspan, Alan. 2003. Opening Remarks at "Monetary Policy under Uncertainty," symposium sponsored by the Federal Reserve Bank of Kansas City, Jackson Hole, Wyoming.

Gurkaynak, Refet, Brian Sack, and Eric Swanson. 2005. "The Sensitivity of Long-Term Interest Rates: Evidence and Implications for Macroeconomic Models." American Economic Review 95(1), pp. 425436.

Knight, Frank. 1921. Risk, Uncertainty, and Profit. Boston: Houghton Mifflin Co.

Levin, Andrew,Volker Wieland, and John Williams. 2003. "The Performance of Forecast-Based Monetary Policy Rules under Model Uncertainty." American Economic Review 93(3), pp. 622-645.

McCallum, Bennett. 1988. "Robustness Properties of a Rule for Monetary Policy." Carnegie-Rochester Conference Series on Public Policy 29, pp. 175-203.

Orphanides, Athanasios. 2001. "Monetary Policy Rules Based on Real-Time Data." American Economic Review 91(4), pp. 964-985.

Orphanides, Athanasios, and John Williams. 2005. "Inflation Scares and Forecast-Based Monetary Policy." Review of Economic Dynamics 8(2), pp. 498527.

Rudebusch, Glenn. 2001. "Is the Fed Too Timid? Monetary Policy in an Uncertain World." Review of Economics and Statistics 83(2), pp. 203-217.

Sargent, Thomas. 1999. "Comment: Policy Rules for Open Economies." In Monetary Policy Rules, ed. John Taylor. Chicago: University of Chicago Press.

Söderström, Ulf. 2002. "Monetary Policy with Uncertain Parameters." Scandinavian Journal of Economics 104(1), pp. 125-145. 


\section{P.O. Box 7702}

San Francisco, CA 94120

Address Service Requested

IT Investment:Will the Glory Days Ever Return? Stress Tests: Useful Complements to Financial Risk Models Age and Education Effects on the Unemployment Rate Understanding the Twin Deficits: New Approaches, New Results What If Foreign Governments Diversified Their Reserves? Monetary Policy and Asset Price Bubbles Does Europe's Path to Monetary Union Provide Lessons for East Asia? Credit Union Failures and Insurance Fund Losses: 1971-2004 Housing Markets and Demographics Policymaking on the FOMC:Transparency and Continuity A Look at China's New Exchange Rate Regime Why Has Output Become Less Volatile? Inflation Expectations: How the Market Speaks The Rise and Spread of State R\&D Tax Credits Estimating the "Neutral" Real Interest Rate in Real Time Oil Price Shocks and Inflation Economies of Scale and Continuing Consolidation of Credit Unions Spendthrift Nation Why Hasn't the Jump in Oil Prices Led to a Recession? The Bretton Woods System: Are We Experiencing a Revival?
Doms

Lopez

Valletta/Hodges

Cavallo

Valderrama

Rudebusch

Glick

Wilcox

Krainer

Yellen

Spiegel

Trehan

Kwan

Wilson

Wu

Trehan

Wilcox

Lansing

Fernald/Trehan

Glick/Spiegel

Opinions expressed in the Economic Letter do not necessarily reflect the views of the management of the Federal Reserve Bank of San Francisco or of the Board of Governors of the Federal Reserve System. This publication is edited by Judith Goff, with the assistance of Anita Todd. Permission to reprint portions of articles or whole articles must be obtained in writing. Permission to photocopy is unrestricted. Please send editorial comments and requests for subscriptions, back copies, address changes, and reprint permission to: Public Information Department, Federal Reserve Bank of San Francisco, P.O. Box 7702, San Francisco, CA 94120, phone (415) 974-2163, fax (415) 974-3341, e-mail sf.pubs@sf.frb.org. The Economic Letter and other publications and information are available on our website, http://www.frbsf.org. 